\title{
Relationship between time to target temperature and outcome in patients treated with therapeutic hypothermia after cardiac arrest
}

\author{
Moritz Haugk, Christoph Testori, Fritz Sterz ${ }^{*}$, Maximilian Uranitsch, Michael Holzer, Wilhelm Behringer and \\ Harald Herkner, for the Time to Target Temperature Study Group
}

\begin{abstract}
Introduction: Our purpose was to study whether the time to target temperature correlates with neurologic outcome in patients after cardiac arrest with restoration of spontaneous circulation treated with therapeutic mild hypothermia in an academic emergency department.

Methods: Temperature data between April 1995 and June 2008 were collected from 588 patients and analyzed in a retrospective cohort study by observers blinded to outcome. The time needed to achieve an esophageal temperature of less than $34^{\circ} \mathrm{C}$ was recorded. Survival and neurological outcomes were determined within six months after cardiac arrest.

Results: The median time from restoration of spontaneous circulation to reaching a temperature of less than $34^{\circ} \mathrm{C}$ was 209 minutes (interquartile range [IQR]: 130-302) in patients with favorable neurological outcomes compared to 158 min (IQR: 101-230) $(P<0.01)$ in patients with unfavorable neurological outcomes. The adjusted odds ratio for a favorable neurological outcome with a longer time to target temperature was 1.86 ( $95 \% \mathrm{Cl} 1.03$ to $3.38, P=0.04$ ).

Conclusions: In comatose cardiac arrest patients treated with therapeutic hypothermia after return of spontaneous circulation, a faster decline in body temperature to the $34^{\circ} \mathrm{C}$ target appears to predict an unfavorable neurologic outcome.
\end{abstract}

\section{Introduction}

For patients who have been successfully resuscitated after cardiac arrest, therapeutic mild hypothermia increases the rate of a favorable outcome in comparison with standard life support. Randomized controlled trials, however, have not shown evidence of whether the time to target temperature correlates with neurological outcome [1-4]. Registries about the practical use of therapeutic hypothermia have also not found a significant association between the timing of therapeutic hypothermia and final outcome [5-7]. We expected a strong relationship between the time to target temperature $\left(<34^{\circ} \mathrm{C}\right)$ and neurological outcome. Furthermore, we hypothesized that earlier achievement of target temperature would not necessarily improve outcome.

\footnotetext{
* Correspondence: fritz.sterz@meduniwien.ac.at

Department of Emergency Medicine, Medical University of Vienna, Währinger Gürtel 18-20/6D, Wien, 1090, Austria
}

\section{Materials and methods}

The study was designed as a single-center retrospective cohort study on temperature data extracted from patients' charts by observers blinded to outcome. The protocol and consent procedures were approved by the ethics committee of the Medical University of Vienna and were performed in accordance with the Declaration of Helsinki. This trial qualified for exception from informed consent requirements for emergency research as outlined in the applicable national laws of Austria. The subjects enrolled were in an immediate lifethreatening situation, unconscious, and unable to provide consent for trial enrollment and had a mortality approaching $75 \%$. As cardiac arrest is frequently the first manifestation of cardiovascular disease, there was no way to prospectively identify individuals who would become eligible for this trial. However, investigators attempted to notify family members that the subjects

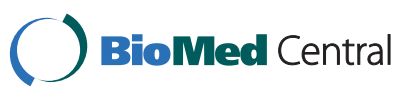

(c) 2011 Haugk et al.; licensee BioMed Central Ltd. This is an open access article distributed under the terms of the Creative Commons Attribution License (http://creativecommons.org/licenses/by/2.0), which permits unrestricted use, distribution, and reproduction in any medium, provided the original work is properly cited. 
had been enrolled. In the event that a patient became competent during the trial period, he or she was approached as soon as feasible by research personnel for notification of enrollment. Data were collected at the Department of Emergency Medicine of the Medical University in Vienna between April 1995 and June 2008 and included data of reports on the same patients $[1,8-12]$ but did not include data focusing on the details of the time to target temperature (Table 1). Participants were consecutive emergency department patients after cardiac arrest in whom spontaneous circulation had been restored and who were receiving therapeutic hypothermia with intensive care in accordance with a standardized protocol $[8,13,14]$.

Neurologic morbidity (a) and mortality (b) were independently compared with the time to target temperature. Neurologic outcome was measured as a Pittsburgh cerebral performance category (CPC) on a five-category scale $[15,16]$. Patients with good recovery or moderate disability had sufficient cerebral function to live independently and work at least part-time (best CPC 1-2). The Pittsburgh CPCs were assessed on a regular basis by means of structured patient interviews.

The temperature immediately on admission was measured with an infrared tympanic thermometer (Ototemp LighTouch; Exergen Corporation, Watertown, MA, USA). Continuous temperature measurements were made as soon as possible in the commencement of therapeutic cooling with a bladder-temperature probe (Foley catheter temperature sensor; Smiths Medical, Dublin, $\mathrm{OH}, \mathrm{USA}$ ) and with a general-purpose temperature probe (Mon-a-therm General purpose; Mallinckrodt Medical Inc., now part of Covidien, Hazelwood, MO, USA) inserted in the esophagus. Temperature-monitoring data were extracted from patient charts by two independently operating staff members. Temperature recordings in the tympanum, esophagus, and bladder were registered with regard to when the first measurement after restoration of spontaneous circulation was available: at the start of cooling and at the first

Table 1 Characteristics of patients in the study

\begin{tabular}{|c|c|c|c|c|}
\hline & & e to target temperat & & \\
\hline & $<120$ minutes & 120 to 220 minutes & $>220$ minutes & $P$ value \\
\hline Age, years & $56(45-67)$ & $60(51-71)$ & $58(49-66)$ & 0.34 \\
\hline Male & $40(65 \%)$ & $48(67 \%)$ & $59(82 \%)$ & 0.05 \\
\hline Height, cm & $175(165-180)$ & $175(165-180)$ & $177(171-180)$ & 0.01 \\
\hline Weight, kg & $78(70-85)$ & $80(71-90)$ & $85(75-95)$ & 0.002 \\
\hline Cardiac arrest & & & & \\
\hline Out-of-hospital & $60(97 \%)$ & $64(89 \%)$ & $67(93 \%)$ & 0.21 \\
\hline Cardiac etiology & $40(65 \%)$ & $54(75 \%)$ & $57(79 \%)$ & 0.15 \\
\hline Witnessed & $53(85 \%)$ & $66(92 \%)$ & $63(88 \%)$ & 0.52 \\
\hline Bystander BLS ${ }^{a}$ & $24(39 \%)$ & $20(28 \%)$ & $16(22 \%)$ & 0.10 \\
\hline 1st ECG, VF $N T^{b}$ & $34(55 \%)$ & $46(64 \%)$ & $52(72 \%)$ & 0.11 \\
\hline Defibrillations & $2(0-3)$ & $2(1-5)$ & $2(1-5)$ & 0.55 \\
\hline Adrenaline, mg & $3(1-4)$ & $2(1-4)$ & $3(1-4)$ & 0.58 \\
\hline No-flow ${ }^{c}$, minutes & $3(1-10)$ & $3(0-7)$ & $5(1-8)$ & 0.51 \\
\hline Low-flow ${ }^{d}$, minutes & $20(14-27)$ & $16(10-22)$ & $11(9-23)$ & 0.02 \\
\hline ROSC to admission, minutes & $31(25-42)$ & $36(24-54)$ & $39(26-51)$ & 0.25 \\
\hline ROSC to cool, minutes & $58(29-72)$ & $101(58-130)$ & $86(43-130)$ & 0.001 \\
\hline ROSC to awakeninge, days & $5(3-9)$ & $4(2-6)$ & $4(3-7)$ & 0.59 \\
\hline ROSC to discharge, days & $27(17-51)$ & $30(20-46)$ & $28(21-45)$ & 0.85 \\
\hline ROSC to death, days & $7(3-14)$ & $6(3-30)$ & $18(6-83)$ & 0.05 \\
\hline Best $\mathrm{CPC}^{\mathrm{f}}$ & $4(1-4)$ & $3(1-4)$ & $1(1-4)$ & 0.006 \\
\hline Favorable neurologic outcome & $23(37 \%)$ & $34(47 \%)$ & $45(63 \%)$ & 0.01 \\
\hline Survivors & $30(48 \%)$ & $36(50 \%)$ & $40(56 \%)$ & 0.68 \\
\hline
\end{tabular}

Temperature data between April 1995 and June 2008 were collected from 588 patients. The best cerebral performance category (CPC) achieved within 6 months after cardiac arrest was used; this was not available in 17 patients who died during anesthesia. Data are presented as median (interquartile range) and as number (percentage). The Kruskal-Wallis test for continuous data and chi-square test for categorical data were used to compare variables between the surviving and

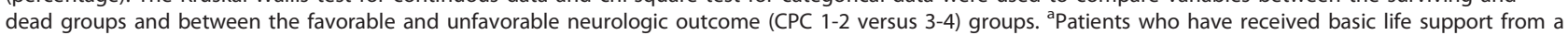
bystander. ${ }^{\mathrm{b}} \mathrm{Cardiac}$ arrest with ventricular fibrillation or nonperfusing ventricular tachycardia as the initial cardiac rhythm on electrocardiogram. ${ }^{\mathrm{C}} \mathrm{Cardiac}$ arrest

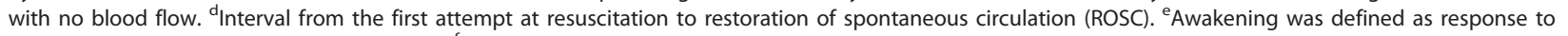
external stimuli with purposeful movements. ${ }^{\mathrm{f}} \mathrm{A}$ CPC of 1 indicates good cerebral performance (the patient is alert and has normal cerebral function). A CPC of 2 indicates moderate disability (the patient is alert and has sufficient cerebral function to live independently and work part-time). Such patients might have hemiplegia, seizures, ataxia, dysarthria, dysphasia, or permanent memory loss, or other mental changes. A CPC of 3 indicates severe cerebral disability (the patient is conscious but dependent on others for daily support because of impaired brain function). A CPC of 4 indicates a vegetative state. 
temperature recording of less than $34^{\circ} \mathrm{C}$ and $33^{\circ} \mathrm{C}$ (Tables 2 and 3). Data on cardiac arrest for individual patients were recorded in a database according to the Utstein style $[15,16]$.

The exposure of interest was the time needed from restoration of spontaneous circulation to achieve a temperature of less than $34^{\circ} \mathrm{C}$. Esophageal temperature was chosen because it is considered to be more reliable than urinary bladder or tympanic temperature in reflecting core body temperature $[17,18]$. The primary outcome was a favorable neurological outcome, defined as best CPC 1 (good recovery) or 2 (moderate disability) within 6 months after cardiac arrest. The secondary outcome was all-cause mortality within 6 months of arrest.

\section{Statistical analysis}

We reported continuous variables as medians and 25\% to $75 \%$ interquartile ranges (IQRs) because they were not generally normally distributed. Categorical variables are reported as counts and percentages. The MannWhitney $U$ test was used to test the null hypothesis of no difference in time to target temperature. To estimate the size of this effect, we used logistic regression analysis, and favorable neurological outcome was the dependent variable. We categorized the predictor time to target temperature into tertiles of time from restoration of spontaneous circulation to esophageal temperature of not more than $34^{\circ} \mathrm{C}(<120,120$ to 220 , and $>220 \mathrm{~min}$ utes) because the assumption of a linear effect did not hold when used as a continuous variable despite standard transformations. Potential confounders were identified by inspection after tabulating them along with exposure and outcome. For formal hypothesis testing, we used the Mann-Whitney $U$ test, the Fisher exact test, or the Pearson chi-square test as appropriate (Tables 1 , $2,3)$. To adjust the effect of time to target temperature on neurological outcome to potential confounders, we developed a multivariable logistic regression model. For covariates, we included factors that were associated with exposure as well as with outcome in our bivariate analyses but were not considered to be part of the causal pathway from exposure to the outcome. These factors included age, total amount of adrenaline needed to achieve restoration of spontaneous circulation, temperature at beginning of cooling, cardiac arrest with ventricular fibrillation, and nonperfusing ventricular tachycardia as the initial cardiac rhythm (Table 4). Time to restoration of spontaneous circulation, no-flow time, and adrenaline dose were closely correlated to each other, so we included only adrenaline dose as the most robust variable in the model to cope with co-linearity. The likelihood ratio test was used to assess deviations from linearity and first-order interactions. The HosmerLemeshow goodness-of-fit statistic indicated a poor fit if the resulting significance value was less than 0.05 . We calculated bootstrapped 95\% confidence intervals. This procedure was repeated for overall survival as the secondary outcome. Stata software (version 8.1; StataCorp LP, College Station, TX, USA) was used to analyze the data. A two-sided $P$ value of less than 0.05 was generally considered to be statistically significant.

\section{Results}

A total of 2,536 cardiac arrest patients were assessed; 1,948 of these patients were not cooled. Thus, 588 patients following the treatment algorithm were studied; they included (a) a group of $285(48 \%)$ patients with favorable outcomes and (b) a group of 284 (48\%) survivors (Tables 1,2,3). All patients included in the analysis were available for follow-up neurologic status evaluation; 17 patients died during sedation, analgesia, and paralysis. At baseline, the patients in the group comparing morbidity were generally similar to the group comparing mortality (Table 1 ). The methods and strategies used for cooling were not different between groups.

Table 2 Temperatures in degrees Celsius in correlation to morbidity and mortality

\begin{tabular}{|c|c|c|c|c|c|c|}
\hline & $\begin{array}{c}\text { Best CPC 1-2 } \\
285(48)\end{array}$ & $\begin{array}{c}\text { Best CPC 3-4 } \\
286(49)\end{array}$ & $P$ value & $\begin{array}{l}\text { Survivors } \\
284(48)\end{array}$ & $\begin{array}{c}\text { Dead } \\
304(52)\end{array}$ & $P$ value \\
\hline $\mathrm{T}_{\text {ty }} 1 \mathrm{st}$ & $35.3(34.6-36)$ & $35.4(34.5-36.1)$ & 0.92 & $35.2(34.4-36)$ & $35.5(34.7-36.2)$ & 0.05 \\
\hline $\mathrm{T}_{\text {ty }}$ cool start & $35.1(34.1-35.8)$ & $34.5(33.6-35.7)$ & 0.15 & $34.6(33.8-35.4)$ & $34.9(33.9-35.9)$ & 0.29 \\
\hline $\mathrm{T}_{\text {es }} 1 \mathrm{st}$ & $35.9(34.9-36.4)$ & $35.2(34.2-36)$ & 0.05 & $35.7(34.9-36.4)$ & $35.2(34.5-36.4)$ & 0.32 \\
\hline $\mathrm{T}_{\text {es }}$ cool start & $35.6(34.8-36.2)$ & $35.1(34.2-35.9)$ & $<0.01$ & $35.2(34.5-36)$ & $35.5(34.6-36.1)$ & 0.27 \\
\hline $\mathrm{T}_{\mathrm{bl}} 1 \mathrm{st}$ & $35.6(34.9-36.2)$ & $35.3(34.6-35.9)$ & 0.09 & $35.4(34.7-36)$ & 35.5 (34.9-36) & 0.98 \\
\hline $\mathrm{T}_{\mathrm{bl}}$ cool start & $35.8(34.9-36.5)$ & $35.4(34.6-36.1)$ & $<0.01$ & $35.7(34.6-36.3)$ & $35.6(34.7-36.3)$ & 0.95 \\
\hline
\end{tabular}

Temperature data between April 1995 and June 2008 were collected from 588 patients. The best cerebral performance category (CPC) achieved within 6 months after cardiac arrest was used; this was not available in 17 patients who died during anesthesia. Data are presented as median (interquartile range). The twosample Wilcoxon rank-sum (Mann-Whitney) test and Fisher exact test, as appropriate, were used to compare variables in the surviving and dead groups and the favorable and unfavorable neurologic outcome (CPC 1-2 versus 3-4) groups. $T_{b}$, bladder temperature; $T_{\text {es }}$, esophageal temperature; $T_{t y}$, tympanic temperature. 
Table 3 Minutes to target temperature in correlation to morbidity and mortality

\begin{tabular}{|c|c|c|c|c|c|c|}
\hline & $\begin{array}{c}\text { Best CPC 1-2 } \\
285(48)\end{array}$ & $\begin{array}{c}\text { Best CPC 3-4 } \\
286(49)\end{array}$ & $P$ value & $\begin{array}{l}\text { Survivors } \\
284 \text { (48) }\end{array}$ & $\begin{array}{c}\text { Dead } \\
304(52)\end{array}$ & $P$ value \\
\hline ROSC to $T_{\text {ty }} 1 \mathrm{st}$ & $29(29-58)$ & $29(29-58)$ & 0.23 & $29(29-58)$ & $29(29-58)$ & 0.59 \\
\hline ROSC to CoolStart & $86(43-144)$ & $86(58-115)$ & 0.44 & $86(58-130)$ & $86(43-130)$ & 0.27 \\
\hline ROSC to $T_{\text {ty }} \leq 34^{\circ} \mathrm{C}$ & $144(94-230)$ & $144(115-245)$ & 0.77 & $151(94-187)$ & $130(115-245)$ & 0.56 \\
\hline ROSC to $T_{\text {ty }} \leq 33^{\circ} \mathrm{C}$ & $173(130-230)$ & $173(122-230)$ & 0.92 & $180(130-216)$ & $144(130-245)$ & 0.94 \\
\hline ROSC to $T_{\text {es }} 1 \mathrm{st}$ & $58(29-58)$ & $43(29-65)$ & 0.50 & $50(29-58)$ & $58(29-86)$ & 0.28 \\
\hline ROSC to CoolStart & $86(43-144)$ & $86(58-115)$ & 0.44 & $86(58-130)$ & $86(43-130)$ & 0.27 \\
\hline ROSC toTes $<34^{\circ} \mathrm{C}$ & $209(130-302)$ & $158(101-230)$ & $<0.01$ & $202(115-259)$ & $158(101-230)$ & 0.57 \\
\hline ROSC to $\mathrm{T}_{\text {es }}<33^{\circ} \mathrm{C}$ & $274(202-389)$ & $245(144-374)$ & 0.02 & $259(166-367)$ & 259 (158-389) & 0.68 \\
\hline ROSC to $T_{b l} 1 s t$ & $58(29-86)$ & $58(29-72)$ & 0.29 & $58(29-72)$ & $58(29-86)$ & 0.62 \\
\hline ROSC to CoolStart & $86(43-144)$ & $86(58-115)$ & 0.44 & $86(58-130)$ & $86(43-130)$ & 0.27 \\
\hline ROSC to $T_{b l}<34^{\circ} \mathrm{C}$ & $230(158-360)$ & $194(115-288)$ & $<0.01$ & $216(144-288)$ & $216(144-346)$ & 0.73 \\
\hline ROSC to $T_{b l}<33^{\circ} \mathrm{C}$ & $346(245-504)$ & $288(187-418)$ & $<0.01$ & $331(245-475)$ & $317(216-446)$ & 0.43 \\
\hline Coolstart to $T_{\text {ty }}<34^{\circ} \mathrm{C}$ & $29(0-43)$ & $14(0-115)$ & 0.95 & $14(0-43)$ & $29(0-115)$ & 0.42 \\
\hline Coolstart to $\mathrm{T}_{\text {ty }}<33^{\circ} \mathrm{C}$ & $29(14-72)$ & $50(14-137)$ & 0.17 & $36(14-101)$ & $58(29-130)$ & 0.35 \\
\hline Coolstart to $\mathrm{T}_{\mathrm{es}}<34^{\circ} \mathrm{C}$ & $86(43-144)$ & $58(29-115)$ & 0.01 & $72(43-130)$ & $72(29-144)$ & 0.72 \\
\hline Coolstart to $\mathrm{T}_{\text {es }}<33^{\circ} \mathrm{C}$ & $173(86-274)$ & $115(58-245)$ & 0.03 & $137(72-245)$ & $144(72-245)$ & 0.32 \\
\hline CoolStart to $\mathrm{T}_{\mathrm{bl}}<34^{\circ} \mathrm{C}$ & $115(72-216)$ & $86(43-187)$ & $<0.01$ & $101(58-202)$ & $101(58-216)$ & 0.98 \\
\hline CoolStart to $\mathrm{T}_{\mathrm{bl}}<33^{\circ} \mathrm{C}$ & $245(144-418)$ & $187(101-317)$ & 0.01 & $216(115-389)$ & $202(101-331)$ & 0.31 \\
\hline
\end{tabular}

Temperature data between April 1995 and June 2008 were collected from 588 patients. The best cerebral performance category (CPC) achieved within 6 months after cardiac arrest was used; this was not available in 17 patients who died during anesthesia. Data are presented as median (interquartile range). The twosample Wilcoxon rank-sum (Mann-Whitney) test was used to compare variables in the surviving and dead groups and the favorable and unfavorable neurologic outcome (CPC 1-2 versus 3-4) groups. ROSC, restoration of spontaneous circulation; $T_{b l}$, bladder temperature; $T_{e s}$, esophageal temperature; $T_{t y}$, tympanic temperature.

In all patients, more initial temperature recordings were available from the tympanum $(n=313)$ than from the esophagus $(n=102)$ or bladder $(n=179)$, and there were no differences between groups (Table 2). The time from restoration of spontaneous circulation until the temperature recordings at cooling start in the tympanum $(n=112)$, esophagus $(n=177)$, and bladder $(n=$ 276) did not differ significantly between the groups
(Table 2 and Figure 1). Time variables are presented in Table 3.

We found $86 \%$ higher odds of a favorable neurological outcome with an increase in each tertile of time to target temperature (adjusted odds ratio 1.86, 95\% confidence interval 1.03 to $3.38 ; P=0.04$ ) (Table 4 ). The median time needed to achieve an esophageal temperature of less than $34^{\circ} \mathrm{C}$ was not associated with overall

Table 4 Multivariable logistic regression for favorable outcome

\begin{tabular}{|c|c|c|}
\hline & $\begin{array}{c}\text { Odds ratio } \\
\text { (bootstrapped } 95 \% \text { confidence intervals) }\end{array}$ & $P$ value \\
\hline Time to target temperature ${ }^{a}$ - crude & $1.69(1.22-2.34)$ & 0.002 \\
\hline Time to target temperature ${ }^{a, b}$ & $1.86(1.03-3.38)$ & 0.04 \\
\hline \multicolumn{3}{|l|}{ Time to target temperature adjusted for } \\
\hline Age, years & $0.95(0.92-0.99)$ & 0.01 \\
\hline Epinephrine, $\mathrm{mg}^{\mathrm{c}}$ & $0.70(0.46-1.04)$ & 0.08 \\
\hline $\mathrm{T}_{\mathrm{bl}} \mathrm{cool}$ start, ${ }^{\circ} \mathrm{C}^{\mathrm{d}}$ & $1.08(0.71-1.63)$ & 0.72 \\
\hline 1st ECG, VFe & $2.54(0.84-7.71)$ & 0.10 \\
\hline
\end{tabular}

a Linear effect for tertiles of time from restoration of spontaneous circulation (ROSC) to esophageal temperature of not more than $34^{\circ} \mathrm{C}(<120,120$ to 220 , and $>220$ minutes). ${ }^{b}$ Hosmer-Lemeshow chi-squared $=2.67, P=0.85$, indicating good model fit. Temperature data between April 1995 and June 2008 were collected from 588 patients. 'Total amount of epinephrine in milligrams needed to achieve ROSC. ${ }^{\mathrm{d} B l a d d e r}$ temperature in degrees Celsius at beginning of cooling. ${ }^{\text {e}}$ Cardiac arrest with ventricular fibrillation or nonperfusing ventricular tachycardia as the initial cardiac rhythm on electrocardiogram. 

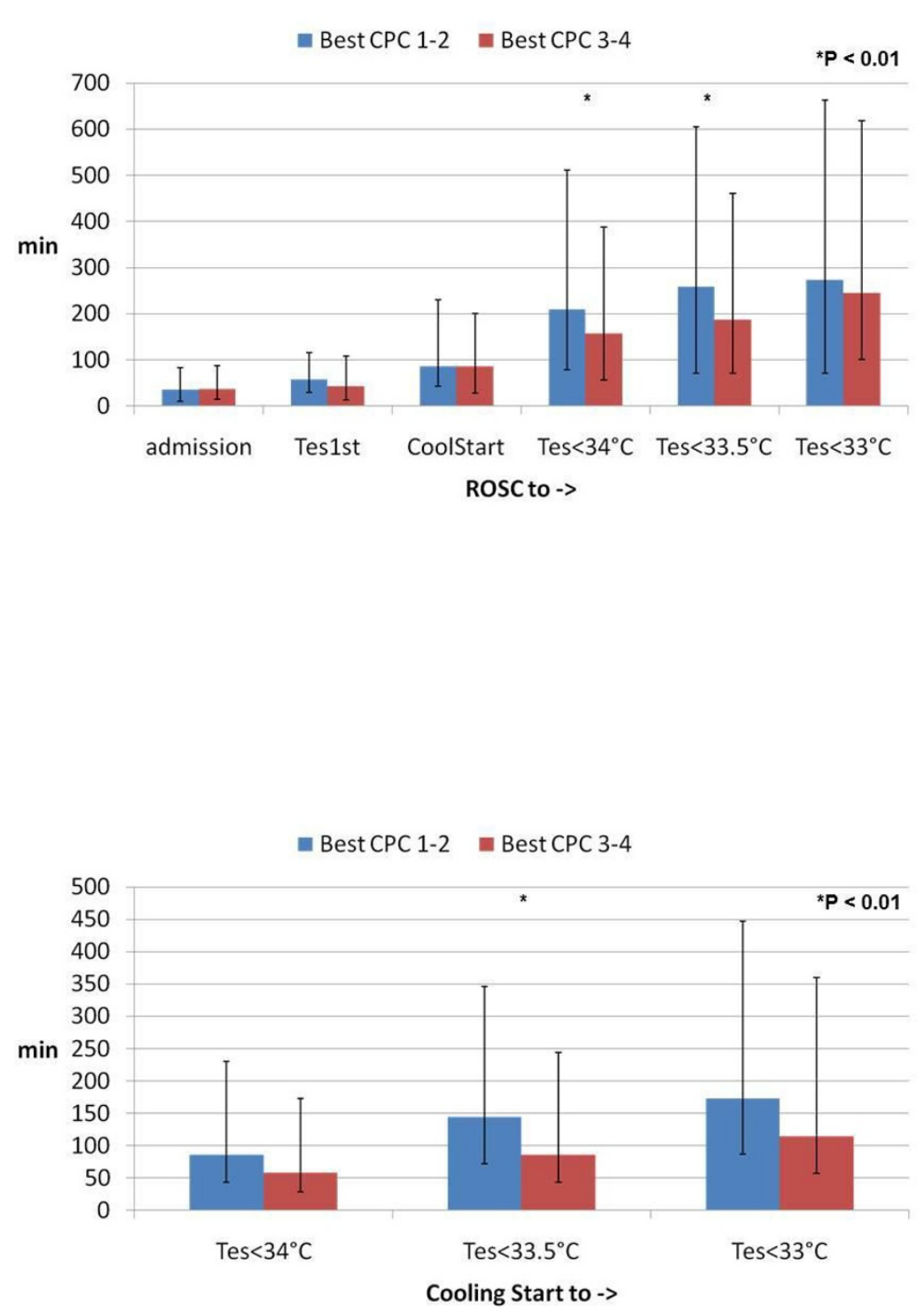

Figure 1 Time to Target Temperature (T2TT) correlated to the best cerebral perforemance catergory (CPC). Temperature data between April 1995 and June 2008 were collected from 588 patients. The best cerebral performance category achieved within 6 months after cardiac arrest was used. A CPC of 1 indicates good cerebral performance (the patient is alert and has normal cerebral function). A CPC of 2 indicates moderate disability (the patient is alert and has sufficient cerebral function to live independently and work part-time). Such patients might have hemiplegia, seizures, ataxia, dysarthria, dysphasia or permanent memory loss, or other mental changes. A CPC of 3 indicates severe cerebral disability (the patient is conscious but dependent on others for daily support because of impaired brain function). A CPC of 4 indicates a vegetative state. Time is expressed in minutes from restoration of spontaneous circulation (ROSC) to hospital admission (admission), to first monitored esophageal temperature $\left(T_{\text {es }} 1\right.$ st), to start of cooling (Cool Start), and to esophageal temperature $\left(T_{\text {es }}\right)$ of less than $34^{\circ} \mathrm{C}, 33.5^{\circ} \mathrm{C}$, and $33^{\circ} \mathrm{C}$. Data are presented as median and interquaritle range from the 25 th to the 75 th percentile.

survival (202 minutes, 25\% to $75 \%$ IQR 115 to 259 for survivors versus 158 minutes, $25 \%$ to $75 \%$ IQR 101 to 230 for nonsurvivors) (Table 3 ). Cooling methods used are shown in Table 5.

\section{Discussion}

Our results show a strong relationship between the time to target temperature and neurological outcome among comatose patients in whom spontaneous circulation had been restored after cardiac arrest and therapeutic hypothermia was induced. A shorter time until systemic cooling to an esophageal temperature below $34^{\circ} \mathrm{C}$ seems to be able to predict unfavorable neurologic outcome. If faster cooling is detrimental or patients with more severe neurological damage show a faster cooling rate has to be further evaluated. 
Table 5 Cooling methods in correlation to morbidity and mortality

\begin{tabular}{|c|c|c|c|c|c|c|}
\hline & $\begin{array}{c}\text { Survivors } \\
284(48)\end{array}$ & $\begin{array}{c}\text { Dead } \\
304(52)\end{array}$ & $P$ value & $\begin{array}{c}\text { Best CPC 1-2 } \\
285(48)\end{array}$ & $\begin{array}{c}\text { Best CPC 3-4 } \\
286(49)\end{array}$ & $P$ value \\
\hline \multicolumn{7}{|l|}{ Cooling method } \\
\hline Endovascular & $60(21)$ & $58(19)$ & 0.60 & $65(23)$ & $53(17)$ & 0.56 \\
\hline Head & $10(4)$ & $7(2)$ & 0.54 & $6(2)$ & $11(4)$ & 0.13 \\
\hline Surface ice & $43(15)$ & $36(12)$ & 0.62 & $29(10)$ & $50(17)$ & 0.01 \\
\hline Nasopharyngeal & $7(2)$ & $7(2)$ & 0.95 & $5(2)$ & $9(3)$ & 0.18 \\
\hline IV & $10(4)$ & $10(3)$ & 0.94 & $8(3)$ & $12(4)$ & 0.22 \\
\hline IV + endovascular & $51(18)$ & $55(18)$ & 0.68 & $52(18)$ & $54(18)$ & 0.38 \\
\hline IV + surface air & $5(2)$ & $9(3)$ & 0.29 & $5(2)$ & $9(3)$ & 0.18 \\
\hline IV + surface ice & $6(2)$ & $8(3)$ & 0.57 & $6(2)$ & $8(3)$ & 0.39 \\
\hline IV + surface water & $5(2)$ & $8(3)$ & 0.40 & $11(4)$ & $2(1)$ & 0.06 \\
\hline Surface air & $39(14)$ & $65(21)$ & 0.05 & $53(19)$ & $51(17)$ & 0.54 \\
\hline Surface water & $30(11)$ & $27(9)$ & 0.82 & $24(8)$ & $33(11)$ & 0.11 \\
\hline Surface waterbath & $8(3)$ & $2(1)$ & 0.15 & $8(3)$ & $2(1)$ & 0.15 \\
\hline Other or mixed & $13(5)$ & $9(3)$ & 0.48 & $13(5)$ & $9(3)$ & 0.73 \\
\hline Invasive cooling & $155(55)$ & $160(53)$ & & $161(56)$ & $154(51)$ & \\
\hline Noninvasive cooling & $129(45)$ & $144(47)$ & 0.68 & $124(44)$ & $149(49)$ & 0.19 \\
\hline Out-of-hospital cooling & $25(9)$ & $23(8)$ & & $19(7)$ & $29(10)$ & \\
\hline In-hospital cooling & $259(91)$ & $281(92)$ & 0.65 & $266(93)$ & $274(90)$ & 0.23 \\
\hline No IV cooling & $207(73)$ & $214(70)$ & & $203(71)$ & $218(72)$ & \\
\hline IV cooling alone & $10(4)$ & $10(3)$ & & $8(3)$ & $12(4)$ & \\
\hline IV+ cooling & $67(24)$ & $80(26)$ & 0.75 & $74(26)$ & $73(24)$ & 0.68 \\
\hline
\end{tabular}

Temperature data between April 1995 and June 2008 were collected from 588 patients. Data are presented as number (percentage). Fisher exact test, Pearson chi-square test, and Wald test for comparing the cooling methods with 'endovascular' as reference were used to compare variables, such as favorable and unfavorable neurologic outcome (cerebral performance category [CPC] 1-2 versus 3-4) groups, in the survivors and dead. IV, intravenous.

This study has the limitations of a retrospective, observational, and descriptive single-center registry, but the observers of temperature data were blinded to outcome. All eligible patients may not have been cooled, and many factors in regard to patient heat transfer are not available, particularly in the beginning of post-arrest cooling, which lies in the nature of implementing a new therapeutic strategy. Even if a selection bias exists, the time to target temperature over the years remains a factor independent from any bias. To analyze the effect of the time to target temperature on morbidity and mortality, the cohort was evaluated independently in regard to the best-ever-achieved CPC during the follow-up period and in regard to survival. Therefore, it was necessary to exclude the patients dying during sedation, analgesia, and paralysis from the morbidity evaluation.

Though similar to those in other hypothermia trials, the median time intervals in our study were still lengthy. It took more than 80 minutes to commence cooling therapy and around 3 hours to achieve the target temperature. The time to initiation of cooling was not different between groups, showing that it does not correlate with the time to target temperature. Therefore, it appears that patients with a worse responsiveness to cooling are those with a better outcome; however, this cannot be proven without measuring heat transfer in a prospective trial. Along the same lines, the data show that esophageal temperatures at the beginning of cooling were half a degree lower in patients with unfavorable neurologic outcomes in comparison with those with favorable neurologic outcomes. Thus, patients with unfavorable neurologic outcomes could reach target temperature more quickly. The delay in time to target temperature could reflect a stronger natural homeostatic central-nervous physiological response in those with better outcomes; this might also explain the association with improved outcome but not survival.

The standard for temperature monitoring in our patients after cardiac arrest is to get the first temperature at the tympanum and thereafter as soon as possible in the esophagus and bladder. By presenting the temperature data from the three different sites separately, we want to show that our findings are independently the same (Table 2). This and the long time intervals to initiation of cooling and achieving the target temperature justify basing the calculations only on the ones 
having an esophageal temperature probe and using the initial bladder temperature for the multivariate analysis. Even if temperatures at the beginning of cooling were lower in patients with unfavorable neurologic outcomes, the difference remains with $0.4^{\circ} \mathrm{C}$ marginal (Table 2) and we have controlled for that variable and other confounders in our adjusted analysis (Table 3). However, many known and possibly still unknown confounders have not been taken care of and therefore our results can be used only for hypothesis generating of future trials necessary to answer this and many other questions related to therapeutic hypothermia. In addition, the time to target temperature from start of cooling, reflecting the cooling rate, proved to be shorter in the group with unfavorable neurologic outcomes. The reason for this surprising result might be of an associative nature and could be explained by the compromised thermoregulation with cerebral insults $[12,19]$. The data are important for those planning future prospective studies of early versus delayed cooling.

The findings of the present study appear to be contradictory to the notion that achieving mild therapeutic hypothermia earlier and faster helps to reduce hypoxic brain injury and favors a positive neurologic outcome $[3,20,21]$. It is disappointing that no additional clinical data of patients with cardiac arrest and cooling help to explain that discrepancy. Therefore, all discussions of our findings remain speculative and will not be able to answer whether rapid cooling will cause more hemodynamic changes or other cerebral effects that alter neurologic outcome. Alternatively, it appears that sicker patients lack homeostatic mechanisms to maintain normothermia and therefore cool faster. Unfortunately, the question of how soon cooling should be initiated remains unanswered and prospective human studies have yet to define the ideal time to begin cooling patients [22].

Given the strong effect of therapeutic hypothermia with a protocol chosen on the basis of experimental data, there might be potential to further optimize the treatment and gain an even better neurologic outcome for patients after a global cerebral ischemic event $[20,23]$. At present, hypothermia is initiated mainly inhospital and for arrests with cardiac etiology and a typical clinical presentation. However, there are no data to support whether earlier and faster cooling, already initiated in the out-of-hospital phase, may be better for preserving neurologic function [24-26]. Further studies should attempt to determine the time point at which the initiation of therapeutic hypothermia becomes most beneficial to patients who achieve restoration of spontaneous circulation following cardiac arrest $[7,23]$. Additional research is required to explore the best methods for induction of therapeutic hypothermia, including the most appropriate time and location of therapeutic hypothermia initiation and the optimal means to induce temperature reduction.

\section{Conclusions}

In comatose cardiac arrest patients treated with therapeutic hypothermia after return of spontaneous circulation, a faster decline in body temperature to the $34^{\circ} \mathrm{C}$ target appears to predict a less favorable neurologic outcome. A faster decline in body temperature may simply indicate a more severe ischemic insult with resulting impairments in thermoregulation and thus predicts a worse outcome. Nevertheless, prospective studies should be conducted to confirm this observation and, in turn, address whether such a finding is simply a marker for a more severe insult or whether controlling the rate of cooling could favorably alter the outcome.

\section{Key messages}

- In cardiac arrest managed with therapeutic hypothermia after resuscitation, reaching the $34^{\circ} \mathrm{C}$ target faster retrospectively predicts a poor neurologic outcome.

- A faster decline in body temperature may indicate a more severe ischemic insult with impaired thermoregulation and thus predicts a worse outcome.

- Prospective studies should address whether this finding is simply a marker for a more severe insult or whether controlling the rate of cooling can favorably alter outcome.

\section{Abbreviations}

CPC: cerebral performance category; IQR: interquartile range.

\section{Acknowledgements}

The following investigators participated in the Time to Target Temperature (T2TT) study group of the Universitätsklinik für Notfallmedizin, Vienna, Austria (temperature data collection, acquisition of data, analysis and interpretation of data, involvement in revising the manuscript critically for important intellectual content, and final approval of the version to be published): Jasmin Arrich, Kewan Bayegan, Philip Eisenburger, Roman Fleischhackl, Christoph Havel, Nina Holzer-Richling, Andreas Janata, Andreas Kliegel, Julia Kofler, Klemens Köhler, Julia Koller, Angela Koppensteiner, Danica Krizanac, Anton N Laggner, Heidrun Losert, Reinhard Malzer, Eva Riedmüller, Andreas Schober, Waltarud Schörkhuber, Hanno Sendler (ethics committee submission), Gottfried Sodeck, Peter Stratil, Thomas Uray, Marianne Vlcek, Christian Wallmüller, Cosima Wandaller, and Andrea Zeiner-Schatzl. We are indebted to the nurses and staff for their enthusiastic cooperation and to the patients in the study for their trust and support. This study was supported in part by grants from the Biomedicine and Health Programme (BIOMED 2), implemented under the Fourth RTD Framework Programme 1994-1998 of the European Union (BMH4-CD-96-0667), the Austrian Ministry of Science and Transport (GZ 5.550/12-Pr/4/95 and GZ 650.0251/2-IV/6/96), and the Austrian Science Foundation (P11405-MED).

\section{Authors' contributions}

$\mathrm{WB}, \mathrm{HH}$, and $\mathrm{MHo}$ contributed to the steering and writing committees, to the conception and design, and to the analysis and interpretation of data. $\mathrm{MHa}$ contributed to the writing committee and to the acquisition, analysis, and interpretation of data. FS contributed to the steering and writing 
committees, to the conception and design, and to the acquisition, analysis, and interpretation of data. CT contributed to the writing committee and to the acquisition of data. MU contributed to the temperature data collection, to the writing committee, and to the acquisition and interpretation of data All authors were involved in drafting the manuscript or revising it critically for important intellectual content. All authors read and approved the final manuscript.

\section{Competing interests}

The authors declare that they have no competing interests.

Received: 16 January 2011 Revised: 11 February 2011

Accepted: 25 March 2011 Published: 25 March 2011

\section{References}

1. Holzer M, Cerchiari E, Martens P, Roine R, Sterz F, Eisenburger P, Havel C, Kofler J, Oschatz E, Rohrbach K, Scheinecker W, Schörkhuber W, Behringer W, Zeiner A, Valentin A, De Meyer M, Takunen O, Tiainen M, Hachimi-Idrissi S, Huyegens L, Fischer M, Walger P, Bartsch A, Födisch M, Bonnizoli M, Pagni E, Kaff A, Schneider B, Müllner M: Mild therapeutic hypothermia to improve the neurologic outcome after cardiac arrest. $N$ Engl J Med 2002, 346:549-556.

2. Bernard SA, Gray TW, Buist MD, Jones BM, Silvester W, Gutteridge G, Smith K: Treatment of comatose survivors of out-of-hospital cardiac arrest with induced hypothermia. N Engl J Med 2002, 346:557-563.

3. Wolff B, Machill K, Schumacher D, Schulzki I, Werner D: Early achievement of mild therapeutic hypothermia and the neurologic outcome after cardiac arrest. Int J Cardiol 2009, 133:223-228.

4. Kim F, Olsufka M, Longstreth WT Jr, Maynard C, Carlbom D, Deem S, Kudenchuk P, Copass MK, Cobb LA: Pilot randomized clinical trial of prehospital induction of mild hypothermia in out-of-hospital cardiac arrest patients with a rapid infusion of 4 degrees $C$ normal saline. Circulation 2007, 115:3064-3070.

5. Arrich J: Clinical application of mild therapeutic hypothermia after cardiac arrest. Crit Care Med 2007, 35:1041-1047.

6. Oksanen T, Pettila V, Hynynen M, Varpula T: Therapeutic hypothermia after cardiac arrest: implementation and outcome in Finnish intensive care units. Acta Anaesthesiol Scand 2007, 51:866-871.

7. Nielsen N, Hovdenes J, Nilsson F, Rubertsson S, Stammet P, Sunde K, Valsson F, Wanscher M, Friberg H, Hypothermia Network: Outcome, timing and adverse events in therapeutic hypothermia after out-of-hospital cardiac arrest. Acta Anaesthesio/ Scand 2009, 53:926-934.

8. Holzer M, Mullner M, Sterz F, Robak O, Kliegel A, Losert H, Sodeck G, Uray T, Zeiner A, Laggner AN: Efficacy and safety of endovascular cooling after cardiac arrest: cohort study and Bayesian approach. Stroke 2006, 37:1792-1797.

9. Uray T, Haugk M, Sterz F, Arrich J, Richling N, Janata A, Holzer M, Behringer W: Surface cooling for rapid induction of mild hypothermia after cardiac arrest: design determines efficacy. Acad Emerg Med 2010, 17:360-367.

10. Kliegel A, Janata A, Wandaller C, Uray T, Spiel A, Losert H, Kliegel M, Holzer M, Haugk M, Sterz F, Laggner AN: Cold infusions alone are effective for induction of therapeutic hypothermia but do not keep patients cool after cardiac arrest. Resuscitation 2007, 73:46-53.

11. Haugk M, Sterz F, Grassberger M, Uray T, Kliegel A, Janata A, Richling N, Herkner $H$, Laggner AN: Feasibility and efficacy of a new non-invasive surface cooling device in post-resuscitation intensive care medicine. Resuscitation 2007, 75:76-81.

12. Wandaller C, Holzer M, Sterz F, Wandaller J, Arrich J, Uray T, Laggner AN, Herkner $\mathrm{H}$ : Head and neck cooling after cardiac arrest results in lower jugular bulb than esophageal temperature. Am J Emerg Med 2009, 27:460-465.

13. Zeiner A, Holzer M, Sterz F, Behringer W, Schorkhuber W, Mullner M, Frass $M$, Siostrzonek $P$, Ratheiser K, Kaff A, Laggner AN: Mild resuscitative hypothermia to improve neurological outcome after cardiac arrest. A clinical feasibility trial. Hypothermia After Cardiac Arrest (HACA) Study Group. Stroke 2000, 31:86-94.

14. Holzer M: Targeted temperature management for comatose survivors of cardiac arrest. N Engl J Med 2010, 363:1256-1264.

15. Cummins RO, Chamberlain DA, Abramson NS, Allen M, Baskett PJ, Becker $L$, Bossaert L, Delooz HH, Dick WF, Eisenberg MS, Evans TR, Holmberg S,
Kerber R, Mullie A, Ornato JP, Sandoe E, Skulberg A, Tunstall-Pedoe H, Swanson $\mathrm{R}$, Thies WH: Recommended guidelines for uniform reporting of data from out-of-hospital cardiac arrest: the Utstein Style. A statement for health professionals from a task force of the American Heart Association, the European Resuscitation Council, the Heart and Stroke Foundation of Canada, and the Australian Resuscitation Council. Circulation 1991, 84:960-975.

16. Jacobs I, Nadkarni V, Bahr J, Berg RA, Billi JE, Bossaert L, Cassan P, Coovadia A, D'Este K, Finn J, Halperin H, Handley A, Herlitz J, Hickey R, Idris A, Kloeck W, Larkin GL, Mancini ME, Mason P, Mears G, Monsieurs K, Montgomery W, Morley P, Nichol G, Nolan J, Okada K, Perlman J, Shuster M, Steen PA, Sterz F, et al: Cardiac arrest and cardiopulmonary resuscitation outcome reports: update and simplification of the Utstein templates for resuscitation registries. A statement for healthcare professionals from a task force of the international liaison committee on resuscitation (American Heart Association, European Resuscitation Council, Australian Resuscitation Council, New Zealand Resuscitation Council, Heart and Stroke Foundation of Canada, InterAmerican Heart Foundation, Resuscitation Council of Southern Africa). Resuscitation 2004, 63:233-249.

17. Lefrant JY, Muller L, de La Coussaye JE, Benbabaali M, Lebris C, Zeitoun N, Mari C, Saïssi G, Ripart J, Eledjam JJ: Temperature measurement in intensive care patients: comparison of urinary bladder, oesophageal, rectal, axillary, and inguinal methods versus pulmonary artery core method. Intensive Care Med 2003, 29:414-418.

18. Haugk M, Stratil P, Sterz F, Krizanac D, Testori C, Uray T, Losert UM, Sterz F Temperature monitored on the cuff surface of an endotracheal tube reflects body temperature. Crit Care Med 2010, 38:1569-1574.

19. Sessler DI: Thermoregulatory defense mechanisms. Crit Care Med 2009, 37 S203-S210.

20. Neumar RW, Nolan JP, Adrie C, Aibiki M, Berg RA, Bottiger BW, Callaway C, Clark RS, Geocadin RG, Jauch EC, Kern KB, Laurent I, Longstreth WT Jr, Merchant RM, Morley P, Morrison LJ, Nadkarni V, Peberdy MA, Rivers EP, Rodriguez-Nunez A, Sellke FW, Spaulding C, Sunde K, Vanden Hoek T: Postcardiac arrest syndrome: epidemiology, pathophysiology, treatment, and prognostication. A consensus statement from the International Liaison Committee on Resuscitation (American Heart Association, Australian and New Zealand Council on Resuscitation, European Resuscitation Council, Heart and Stroke Foundation of Canada, InterAmerican Heart Foundation, Resuscitation Council of Asia, and the Resuscitation Council of Southern Africa); the American Heart Association Emergency Cardiovascular Care Committee; the Council on Cardiovascular Surgery and Anesthesia; the Council on Cardiopulmonary, Perioperative, and Critical Care; the Council on Clinical Cardiology; and the Stroke Council. Circulation 2008, 118:2452-2483

21. Howes D, Ohley W, Dorian P, Klock C, Freedman R, Schock R, Krizanac D, Holzer M: Rapid induction of therapeutic hypothermia using convectiveimmersion surface cooling: safety, efficacy and outcomes. Resuscitation 2010, 81:388-392.

22. Lyon RM, Richardson SE, Hay AW, Andrews PJ, Robertson CE, Clegg GR: Esophageal temperature after out-of-hospital cardiac arrest: an observational study. Resuscitation 2010, 81:867-871.

23. Majersik JJ, Silbergleit R, Meurer WJ, Brown DL, Lisabeth LD, Morgenstern LB: Public health impact of full implementation of therapeutic hypothermia after cardiac arrest. Resuscitation 2008, 77:189-194.

24. Coimbra C, Wieloch T: Moderate hypothermia mitigates neuronal damage in the rat brain when initiated several hours following transient cerebral ischemia. Acta Neuropathol 1994, 87:325-331.

25. Colbourne F, Corbett D, Zhao ZH, Yang J, Buchan AM: Prolonged but delayed postischemic hypothermia: a long-term outcome study in the rat middle cerebral artery occlusion model. J Cereb Blood Flow Metab 2000, 20:1702-1708.

26. Kuboyama K, Safar P, Radovsky A, Tisherman SA, Stezoski SW, Alexander H: Delay in cooling negates the beneficial effect of mild resuscitative cerebral hypothermia after cardiac arrest in dogs: a prospective, randomized study [see comments]. Crit Care Med 1993, 21:1348-1358.

doi:10.1186/cc10116

Cite this article as: Haugk et al:: Relationship between time to target temperature and outcome in patients treated with therapeutic hypothermia after cardiac arrest. Critical Care 2011 15:R101. 